\title{
BMJ Open Is adequate pain relief and time to analgesia associated with emergency department length of stay? A retrospective study
}

\author{
Catalina Sokoloff, ${ }^{1,2}$ Raoul Daoust, ${ }^{1,2}$ Jean Paquet, ${ }^{1,3}$ Jean-Marc Chauny ${ }^{1,2}$
}

To cite: Sokoloff C,

Daoust R, Paquet J, et al. Is adequate pain relief and time to analgesia associated with emergency department length of stay?

A retrospective study. BMJ Open 2014;4:e004288. doi:10.1136/bmjopen-2013004288

- Prepublication history for this paper is available online. To view these files please visit the journal online (http://dx.doi.org/10.1136/ bmjopen-2013-004288)

Received 23 October 2013 Revised 21 February 2014 Accepted 26 February 2014

CrossMark

For numbered affiliations see end of article.

Correspondence to Dr Raoul Daoust; raoul.daoust@umontreal.ca

\section{ABSTRACT}

Objectives: Evaluate the association of adequate analgesia and time to analgesia with emergency department (ED) length of stay (LOS).

Setting and Design: Post hoc analysis of real-time archived data.

Participants: We included all consecutive ED patients $\geq 18$ years with pain intensity $>6$ (verbal numerical scale from 0 to 10), assigned to an ED bed, and whose pain was re-evaluated less than $1 \mathrm{~h}$ after receiving analgesic treatment.

Outcome measures: The main outcome was ED-LOS in patients who had adequate pain relief (AR $=\downarrow 50 \%$ pain intensity) compared with those who did not have such relief (NR).

Results: A total of 2033 patients (mean age 49.5 years; $51 \%$ men) met our inclusion criteria; $58.3 \%$ were discharged, and $41.7 \%$ were admitted. Among patients discharged or admitted, there was no significant difference in ED-LOS between those with AR (median (25th-75th centile): $9.6 \mathrm{~h}(6.3-14.8)$ and $18.2 \mathrm{~h}(11.6-25.7)$, respectively) and NR (median (25th-75th centile): $9.6 \mathrm{~h}(6.6-16.0)$ and $17.4 \mathrm{~h}$ (11.3-26.5), respectively). After controlling for confounding factors, rapid time to analgesia (not AR) was associated with shorter ED-LOS of discharged and admitted patients $(p<0.001$ and $<0.05$, respectively). When adjusting for confounding variables, ED-LOS is shortened by $2 \mathrm{~h}(95 \% \mathrm{Cl} 1.1$ to 2.8$)$ when delay to receive analgesic is $<90$ min compared with $>90 \mathrm{~min}$ for discharged and by $2.3 \mathrm{~h}(95 \% \mathrm{Cl} 0.17$ to 4.4$)$ for admitted patients.

Conclusions: In our study, AR was not linked with short ED-LOS. However, rapid administration of analgesia was associated with short ED-LOS.

\section{INTRODUCTION}

Emergency department (ED) overcrowding has been a concern for many years, and Canada is no exception, with nearly $60 \%$ of EDs reporting that problem in 2007. ${ }^{1}$ The phenomenon of 'boarding' is one of the principal factors identified as its cause. ${ }^{23}$ 'Boarding' (or
Strengths and limitations of this study

- This is a rare study that examines the association between pain relief and length of stay in a large cohort of emergency department patients.

- This study also controlled for multiples confounding variables.

- The main limitation of our study is its post hoc design and preformed database from a singlecentre study in an academic hospital.

'access block') refers to situations where bedridden emergency patients wait for the allocation of a bed in the ward for an unreasonably long time period (prolonged ED length of stay (LOS) with consequent patient overflow in EDs. However, a recent retrospective study revealed that among patients waiting more than $6 \mathrm{~h}$ in the ED, $50 \%$ were finally admitted while the other $50 \%$ were discharged, ${ }^{4}$ indicating that non-boarding patients' LOS also contributes to overcrowding. It has been shown to be a strong predictor of low satisfaction among patients ${ }^{5}$ and healthcare workers. ${ }^{1}$ It is also associated with long hospital LOS, ${ }^{6} 7$ and high short-term and medium-term mortality rates. ${ }^{8-10}$ Furthermore, overcrowding is linked with reduced timelines and quality of interventions and treatments, ${ }^{11-13}$ including delayed analgesic administration, ${ }^{14}{ }^{15}$ particularly when pain is severe, ${ }^{16}$ all of which contributes to the snowball effect of cumulating waits.

Pain represents more than $40 \%$ of consultations in EDs. ${ }^{17}$ In large studies of patients with moderate-to-severe pain, only $21-68 \%^{18-27}$ received analgesics, and 50-74\% still had moderate-to-severe pain at discharge. ${ }^{17}$ Severe, persistent pain may also lead to unwanted physiological responses, namely, increased adrenergic tone, augmented oxygen consumption, predisposition to hypercoagulability, decreased immune function and heightened risk of delirium. ${ }^{28}{ }^{29}$ Moreover, adequate and 
timely treatment of acute pain could reduce the risk of chronic pain. ${ }^{17}$ The relationship between pain management and LOS has not been studied as a primary outcome. However, a study of intermittent injection versus patient-controlled analgesia (PCA) for sickle cell crisis pain in the ED, established that PCA was associated with a significant reduction in the ED-LOS, although there was no difference in initial or final pain intensity score. ${ }^{30}$

Recent studies have attempted to identify the factors contributing to prolonged ED-LOS. Many of them have already been recognised, namely, number of laboratory examinations required, having to undergo X-ray or scan, the need for more than three medications, and number of consultants. ${ }^{10} 31$ To the best of our knowledge, the adequacy and effectiveness of pain management have never been investigated in this regard. We sought to evaluate which component of initial pain management was associated with ED-LOS reduction. We hypothesised that ED-LOS would be lessened in patients with significant pain relief.

\section{MATERIALS AND METHODS}

Study design

We conducted a post hoc analysis of real-time archived data on all consecutive patients presenting with severe pain at our ED between March 2008 and February 2011. The aim of our study was to assess if pain relief was associated with ED-LOS reduction. As a secondary objective, we evaluated if time to receiving analgesic treatment was linked with lessened ED-LOS.

\section{Setting}

Hôpital du Sacré-Cœur de Montreal is an urban, adult, level I trauma centre with 540 inpatient beds and 60000 ED visits/year. It sustains 22000 hospitalisations annually, of which $51 \%$ are admitted through the ED. The study was approved by the institutional review board.

\section{Selection of participants}

Patients 18 years or older were included if they were assigned to an ED treatment bed, had severe pain at triage (defined as $>6$ on an 11-point verbal numerical scale from 0 to 10$),{ }^{32-34}$ received an analgesic, and had their pain intensity re-evaluated in less than $1 \mathrm{~h}$ after such medication.

Patients were excluded if they died during their ED stay, were pregnant or had been transferred from another hospital. We also excluded patients with altered mental status, intoxicated subjects and anyone with chest pain necessitating emergent percutaneous coronary intervention, because their LOS would be determined by treatments other than pain management.

\section{Data collection}

Data were extracted from computerised information and nursing records in our ED (MedUrge, MediaMed Technologies, Mont-Saint-Hilaire, Québec, Canada).
This system is an integrated and mandatory working tool for all physicians, nursing staff, and any employee involved in the ED healthcare process. It contains all demographic data, triage information (including vital signs, purpose of consultation, and pain level when relevant) as well as any pertinent data collected in real time by nurses during their re-evaluation rounds, including medication administration, and pain intensity.

\section{Data processing}

The cut-off of $>6$ on 10 was chosen because it was felt that lower pain intensity is less likely to warrant observation in itself. ED-LOS was measured in hours from the time of arrival at the ED to discharge or admission to a ward. We defined adequate pain relief (AR) as reduction of $50 \%$ or more of the initial pain level scored on the numerical scale within $1 \mathrm{~h}$ after receiving the first analgesic. The $50 \%$ reduction and the $1 \mathrm{~h}$ threshold are based on previous literature suggesting that they represent a meaningful decline ${ }^{35} 36$ and acceptable delay in managing severe pain. ${ }^{34} 3738$ Initial pain was the one reported on the triage form. Time between arrival and analgesic administration was dichotomised into $\leq 90$ vs $>90 \mathrm{~min}$ and also analysed by three categories $(<1$; between 1 and 2; and $>2 \mathrm{~h}$ ). We selected a $90 \mathrm{~min}$ threshold because it is the median time to analgesia reported in many EDs with a pain scale integrated in their triage assessment. ${ }^{19} 3940$

Our primary outcome was ED-LOS of patients with AR and without adequate pain relief (NR). Our secondary outcome was ED-LOS of patients who received their medication in $\leq 90 \mathrm{~min}$ compared with those who received it after a longer time period.

\section{Data analysis}

Median LOS (25th-75th centile) between groups of patients was compared by the Mann-Whitney $\mathrm{U}$ test and relationship among LOS and continuous predictors by Spearman rank-order correlations. Median differences and their 95\% CI are also reported. All LOS are presented in hours and separately for patients with intravenous versus patients with other than intravenous route of analgesia administration. To examine the relative influence of AR and time to analgesia on LOS, generalised linear model regressions with $\gamma$-distribution and a $\log$ link function were undertaken for patients discharged from the ED and those admitted to a ward, controlling for age, gender, route of analgesia administration (intravenous vs other), number of doses of analgesia, type of arrival at ED (ambulance or walk-in), triage priority (high vs low), crowding defined as number of patients in ED beds at the time of arrival, time of day of arrival with high or low LOS (calculated from a database of 162000 patients of 18 years or older assigned to a bed between March 2008 and February 2011 from the same ED and selecting hours of arrival with high LOS and hours of arrival with low LOS), time between arrival and physician's first assessment, number of examinations, 
number of specialty consultations, baseline pain intensity score, trauma versus non-trauma, abdominal pain versus other, need for oxygen and for isolation. Generalised linear model was chosen because LOS is largely skewed and tends to produce less prediction errors than traditional linear regression. ${ }^{41}$ Mean LOS difference and Wald 95\% CI adjusted at mean covariates were produced from estimated marginal means. The Canadian healthcare system being public and free, the presence or absence of insurance was not analysed. $\alpha$-Level was set at 0.05 for all statistical tests. All data were analysed with SPSS V.20 (IBM, Somers, New York, USA).

\section{RESULTS}

A total of 2033 patients met our inclusion and exclusion criteria. Of these patients, about half $(51 \%)$ were male, more than two-third arrived at ED alone, 1186 (58.3\%) were finally discharged and 847 were admitted (table 1).

Among patients who were discharged from the ED, $45.7 \%$ had AR compared with $40.3 \%$ of admitted patients. There was no significant difference in ED-LOS

\begin{tabular}{|c|c|}
\hline Characteristics & $\begin{array}{l}\text { Total } \\
(\mathrm{N}=2033)\end{array}$ \\
\hline Mean age $( \pm S D)$ & $49.5(17)$ \\
\hline Male (\%) & 51 \\
\hline \multicolumn{2}{|l|}{ Triage priority (\%) } \\
\hline High (1-2) & 45.3 \\
\hline Low (3-5) & 54.7 \\
\hline \multicolumn{2}{|l|}{ Arrival (\%) } \\
\hline Ambulance & 29.2 \\
\hline Walk-in & 70.8 \\
\hline Admitted (\%) & 41.7 \\
\hline Discharged & 58.3 \\
\hline Treated with opiates only (\%) & 66.7 \\
\hline Treated with non-opiates only & 11.1 \\
\hline Treated with combination & 22.2 \\
\hline \multicolumn{2}{|l|}{ Route of analgesia administration (\%) } \\
\hline Intravenous & 62 \\
\hline Other & 38 \\
\hline With trauma injury (\%) & 7.6 \\
\hline With abdominal pain (\%) & 39.5 \\
\hline With blood test (\%) & 6.4 \\
\hline With heart-rate monitoring (\%) & 11.7 \\
\hline With oxygen support (\%) & 9.5 \\
\hline In isolation (\%) & 4.5 \\
\hline Mean $( \pm S D)$ baseline pain intensity score & $8.8(1.1)$ \\
\hline Mean ( $( \pm S D)$ final pain intensity score & $5.1(3)$ \\
\hline Median LOS in hours (25th-75th centile) & $12.3(7.8-20.3)$ \\
\hline $\begin{array}{l}\text { Median time between arrival at ED and } \\
\text { analgesic treatment in hours ( } 25 \text { th- } 75 \text { th } \\
\text { centile) }\end{array}$ & $1.8(1.1-3.2)$ \\
\hline $\begin{array}{l}\text { Median time to patient care by physician } \\
\text { in hours ( } 25 \text { th }-75 \text { th centile) }\end{array}$ & $0.72(0.42-1.4)$ \\
\hline
\end{tabular}

between patients with AR compared with those NR ( $p=0.41$ for discharged patients and $p=0.87$ for admitted patients; table 2).

Among patients who were discharged from the ED, $533(45 \%)$ received analgesia in $\leq 90 \mathrm{~min}$, with unadjusted ED-LOS reduction of $2.2 \mathrm{~h}$ (95\% CI 1.4 to $3.0 ; \mathrm{p}<0.001)$ compared with those with $>90 \mathrm{~min}$. The same analysis was applied to patients being admitted: only $265(31 \%)$ received their medication in that interval, and their median unadjusted ED-LOS reduction was $3.9 \mathrm{~h}$ (95\% CI 2.0 to 5.7 ; $<<0.001$; table 2). Median ED-LOS for three different times to receive analgesia is displayed in table 3 .

Tables 4 and 5 show the bivariate relations between LOS and all confounding variables controlled for route of analgesia administration for discharged and admitted patients, respectively. For discharged patients with intravenous route of analgesia administration-only type of arrival, crowding and baseline pain intensity score were not related to LOS; while for other than intravenous route of analgesia administration-type of arrival, triage priority, oxygen support, time of day LOS, crowding and baseline pain intensity score were not associated with LOS. For admitted patients with intravenous route of analgesia administration-triage priority, type of arrival, blood testing, time of day LOS, crowding, number of doses and baseline pain intensity score were not related to LOS; while for other than intravenous route of analgesia administration-gender, triage priority, type of arrival, trauma injury, abdominal pain, time of day LOS and time to patient care by physician were not associated with LOS.

Multivariate analysis showed that when controlling for confounding variables, a brief time period $(\leq 90 \mathrm{~min})$ before analgesic administration (not AR) is associated with shortened ED-LOS for discharged and admitted patients $(\beta=0.16 ; 95 \%$ CI 0.10 to $0.22 ; \mathrm{p}<0.001$ and $\beta=0.09 ; 95 \%$ CI 0.006 to $0.18 ; p<0.05$, respectively). When adjusting for confounding variables, ED-LOS is shortened by $2 \mathrm{~h}$ (95\% CI 1.1 to $2.8 ; \mathrm{p}<0.001)$ when time to receive analgesic is $<90$ compared with $>90 \mathrm{~min}$ for discharged and by $2.3 \mathrm{~h}$ (95\% CI 0.17 to $4.4 ; \mathrm{p}<0.05)$ for admitted patients.

\section{LIMITATIONS}

The main limitation of our study is its post hoc design and preformed database. Potential confounding variables, such as ethnicity and linguistic barrier, which are not recorded in demographic charts of our computerised system, could not be taken into consideration. Time from pain onset, component of chronic pain and pharmacological or non-pharmacological analgesia prior to arrival at the ED were also unknown. Case complexity assessment was difficult, although we controlled for number of examinations, number of consultants, need for oxygen and for isolation, which are markers of complexity. Likewise, we do not know if some patients did 
Table 2 Median unadjusted LOS differences (25th-75th centiles) for pain relief groups and time to analgesia groups

\begin{tabular}{|c|c|c|c|}
\hline & $\begin{array}{l}\text { LOS in hour median } \\
\text { (25th-75th centile) }\end{array}$ & $\begin{array}{l}\text { LOS in hour median } \\
\text { (25th-75th centile) }\end{array}$ & $\begin{array}{l}\text { Median difference } \\
( \pm 95 \% \mathrm{Cl})\end{array}$ \\
\hline $\begin{array}{l}\text { Disposition after ED } \\
\text { Discharged patients } \\
\text { Admitted patients } \\
\text { Total }\end{array}$ & $\begin{array}{c}\text { Adequate relief } \\
9.6(6.3-14.8) \\
18.2(11.6-25.7) \\
11.9(7.8-19.6)\end{array}$ & $\begin{array}{l}\text { No adequate relief } \\
9.6(6.6-16.0) \\
17.4(11.3-26.5) \\
12.6(7.8-20.6)\end{array}$ & $\begin{array}{l}0.02(-0.81 \text { to } 0.86) \\
-0.8(-2.8 \text { to } 1.1) \\
-0.7(-1.6 \text { to } 0.3)\end{array}$ \\
\hline $\begin{array}{l}\text { Disposition after ED } \\
\text { Discharged patients } \\
\text { Admitted patients } \\
\text { Total }\end{array}$ & $\begin{array}{l}\leq 1.5 \text { h delay } \\
8.5(5.8-12.5) \\
15.2(10.4-22.6) \\
10.1(6.6-16.3)\end{array}$ & $\begin{array}{l}>1.5 \text { h delay } \\
10.8(7.3-17.7) \\
19.1(11.8-27.6) \\
14.1(9.0-22.7)\end{array}$ & $\begin{array}{l}2.2^{*}(1.4 \text { to } 3.0) \\
3.9^{*}(2.0 \text { to } 5.7) \\
4.0^{*}(2.3 \text { to } 5.6)\end{array}$ \\
\hline
\end{tabular}

not receive an analgesic nor had suboptimal pain management because of refusal. However, it is doubtful that any of these confounding variables would cause significant differential bias. Finally, our single-centre study in an academic hospital might limit the generalisation of our results.

\section{DISCUSSION}

As far as we know, this is the first investigation to evaluate the impact of pain relief on ED-LOS, and our results demonstrated that rapid administration of analgesia (not AR), is associated with shorter ED-LOS. It has been reported that patients expect to receive pain medication 25-30 min after their arrival, ${ }^{42}$ which coincides with the guidelines of our triage system (Canadian Emergency Department Triage and Acuity Scale). ${ }^{43}$ Unfortunately, this goal is far from being achieved in many EDs, not only in Canada, but also around the world. ${ }^{19} 2742$ This is a persistent problem that dates back to the late $1980 \mathrm{~s}$ when Wilson and Pendleton ${ }^{44}$ first defined the term 'oligoanalgesia'.

Recently, the Pain and Emergency Medicine Initiative study demonstrated that patient satisfaction was associated more with the way ED physicians responded to their symptoms of pain than to the actual result of pain treatment. ${ }^{19}$ Which components of this response to pain were significant was not specified, but a possible part of it was the promptness with which pain was addressed. Patients with severe pain probably associate receiving pain medication quickly with quality of care and are more inclined to accept a medical treatment plan, even if they do not get relief. This might explain why we observed improved ED-LOS with prompt analgesic administration in patients being discharged or admitted.

In our study, the adjusted ED-LOS was $2 \mathrm{~h}$ shorter in discharged patients who received their medication in $\leq 90 \mathrm{~min}$ than in those treated in $>90 \mathrm{~min}$. The rapid administration of analgesia, associated with shorter ED-LOS, could have a significant impact on ED overcrowding. For example, our centre received an average of 5000 patients/year with severe pain on an ED bed. If we extrapolate the proportion of patients who received analgesia in $>90$ min after arrival and the time saved if received in less than 90 min from our study of this population, a bed could be available during $16 \mathrm{~h}$ every day. Such economy of beds would contribute to better throughput of patients and render our EDs more efficient, as espoused by Asplin et $a t^{2}$ with their conceptual model of overcrowding in 2003.

A recent consensus of the Canadian Association of Emergency Physicians has ranked 'ED-LOS' and 'time to

Table 3 Median LOS (25th-75th centiles) for three different times to receive analgesia controlled for route of analgesia administration for discharged and admitted patients

\begin{tabular}{lcc} 
Disposition after ED & $\begin{array}{l}\text { IV LOS in hour median } \\
\text { (25th-75th centile) }\end{array}$ & $\begin{array}{c}\text { Other than IV LOS in hour median } \\
\text { (25th-75th centile) }\end{array}$ \\
\hline $\begin{array}{l}\text { Discharged patients } \\
\text { Time to receive analgesia }\end{array}$ & $(\mathrm{N}=698)$ & $(\mathrm{N}=481)$ \\
$\quad<1 \mathrm{~h}$ & $8.6(6.0-11.8)$ & $6.6(4.4-9.5)$ \\
$\quad$ From 1 to $2 \mathrm{~h}$ & $10.5(6.9-15.9)$ & $8.2(5.4-12.2)$ \\
$>2 \mathrm{~h}$ & $12.9(8.9-18.0)$ & $10.1(6.3-19.2)$ \\
Admitted patients & $(\mathrm{N}=556)$ & $(\mathrm{N}=289)$ \\
Time to receive analgesia & & $17.2(10.7-24.8)$ \\
$\quad<1 \mathrm{~h}$ & $16.4(10.8-23.8)$ & $18.1(10.0-26.4)$ \\
$\quad$ From 1 to $2 \mathrm{~h}$ & $14.9(10.4-22.6)$ & $19.6(12.9-28.7)$ \\
$\quad>2 \mathrm{~h}$ & $18.7(11.6-27.4)$ &
\end{tabular}


Table 4 Relationship between LOS and all confounding variables for discharged patients

\begin{tabular}{|c|c|c|}
\hline Confounding variables & IV LOS in hour $(\mathrm{N}=702)$ & Other than IV LOS in hour $(\mathrm{N}=484)$ \\
\hline Categorical confounders & Median (25th-75th centile) & Median (25th-75th centile) \\
\hline \multicolumn{3}{|l|}{ Gender } \\
\hline Male & $9.5(6.7-15.0)^{\star \star}$ & $8.0(5.5-12.3)^{\star \star}$ \\
\hline Female & $11.1(7.9-16.9)$ & $9.8(6.1-18.4)$ \\
\hline \multicolumn{3}{|l|}{ Triage priority } \\
\hline High (1-2) & $9.7(6.7-15.3)^{\star *}$ & $8.8(5.8-13.1)$ \\
\hline Low (3-5) & $10.8(7.9-17.0)$ & $8.8(5.8-15.0)$ \\
\hline \multicolumn{3}{|l|}{ Arrival } \\
\hline Ambulance & $10.8(7.3-16.3)$ & $8.8(5.7-15.5)$ \\
\hline Walk-in & $10.0(7.2-15.7)$ & $8.7(5.8-13.5)$ \\
\hline \multicolumn{3}{|l|}{ Trauma injury } \\
\hline Yes & $7.1(4.1-13.0)^{\star \star}$ & $6.4(4.6-12.7)^{\star \star}$ \\
\hline No & $10.4(7.3-15.9)$ & $9.0(5.9-14.8)$ \\
\hline \multicolumn{3}{|l|}{ Abdominal pain } \\
\hline Yes & $11.3(7.8-17.5)^{\star \star}$ & $10.5(5.7-13.4)^{\star \star}$ \\
\hline No & $9.6(6.9-14.6)$ & $8.3(6.9-14.6)$ \\
\hline \multicolumn{3}{|l|}{ Blood test } \\
\hline Yes & $16.4(10.2-23.6)^{\star \star}$ & $18.5(11.6-25.0)^{\star \star}$ \\
\hline No & $10.0(7.1-15.5)$ & $8.6(5.8-13.8)$ \\
\hline \multicolumn{3}{|l|}{ Heart-rate monitoring } \\
\hline Yes & $14.6(10.6-24.4)^{\star \star}$ & $12.7(9.2-27.8)^{\star \star}$ \\
\hline No & $9.8(6.9-15.2)$ & $8.2(5.7-13.4)$ \\
\hline \multicolumn{3}{|l|}{ Oxygen support } \\
\hline Yes & $13.5(8.7-23.0)^{\star *}$ & $10.4(8.7-23.0)$ \\
\hline No & $10.0(7.1-15.4)$ & $8.6(5.7-14.0)$ \\
\hline \multicolumn{3}{|l|}{ Isolation } \\
\hline Yes & $22.7(11.3-36.7)^{\star \star}$ & $22.6(11.7-44.3)^{\star \star}$ \\
\hline No & $10.0(7.1-15.7)$ & $8.6(5.8-13.5)$ \\
\hline \multicolumn{3}{|l|}{ Time of day of arrival with } \\
\hline Low LOS & $9.0(7.1-10.7)^{\star \star}$ & $8.6(6.1-10.4)$ \\
\hline High LOS & $11.1(7.2-16.9)$ & $8.8(5.7-15.2)$ \\
\hline Continuous confounders & Spearman rank-order correlation & Spearman rank-order correlation \\
\hline Age & $0.18^{\star \star}$ & $0.09^{\star}$ \\
\hline Crowding & 0.06 & -0.06 \\
\hline Time to patient care by physician & $0.21^{\star *}$ & $0.19^{\star *}$ \\
\hline Number of examinations (range $0-15$ ) & $0.33^{\star *}$ & $0.29^{* *}$ \\
\hline Number of specialist consultations (range $0-8$ ) & $0.41^{\star \star}$ & $0.44^{\star \star}$ \\
\hline Number of doses (range 1-7) & $-0.13^{\star \star}$ & $-0.10^{*}$ \\
\hline Baseline pain intensity score & -0.06 & -0.01 \\
\hline
\end{tabular}

first dose of analgesic' in the top 12 priority indicators of quality care ${ }^{45}$ In the USA, the Joint Commission on Accreditation of Healthcare Organizations mentions 'early intervention' as the first goal in the treatment of acute pain. ${ }^{37}$ Similarly, the Australian National Institute of Clinical Studies ranked 'reduced time to analgesia' as the top priority and is currently working on improving their numbers. ${ }^{42}$

New solutions are being proposed to improve the initial approach to pain management. For example, the simple act of making pain scoring mandatory at triage has been shown to reduce time to analgesia by $45 \mathrm{~min}^{40}$ Extension of this practice could also integrate pain treatment as early as triage to limit further delays. Such measures have been introduced in Australia where nurse-initiated pain protocols are currently being evaluated. A paediatric ED study has shown $50 \%$ reduction of time to analgesia with such a protocol. ${ }^{39}$ Early administration of analgesics has been investigated in prehospital settings, and appears to be safe and effective, particularly with the use of intranasal fentanyl. ${ }^{46}{ }^{47}$ Even if no study has yet shown a benefit of this practice in LOS, it certainly has promising advantages, and further investigations should be considered.

In summary, we found that shorter time to analgesia administration is associated with ED-LOS reduction. This observation supports recent interest in analgesia implementation as early as triage or in prehospital settings to improve the throughput component of the overcrowding phenomenon seen in EDs around the world. 
Table 5 Relationship between LOS and all confounding variables for admitted patients

\begin{tabular}{|c|c|c|}
\hline Confounding variables & IV LOS in hour $(\mathrm{N}=558)$ & Other than IV LOS in hour $(\mathrm{N}=289)$ \\
\hline Categorical confounders & Median (25th-75th centile) & Median (25th-75th centile) \\
\hline \multicolumn{3}{|l|}{ Gender } \\
\hline Male & $15.4(10.5-23.6)^{\star}$ & $18.9(11.4-27.5)$ \\
\hline Female & $18.0(11.7-25.4)$ & $19.5(12.7-27.9)$ \\
\hline \multicolumn{3}{|l|}{ Triage priority } \\
\hline High (1-2) & $16.4(10.4-24.5)$ & $18.4(11.1-25.8)$ \\
\hline Low (3-5) & $17.2(11.7-25.0)$ & $19.5(12.9-27.6)$ \\
\hline \multicolumn{3}{|l|}{ Arrival } \\
\hline Ambulance & $17.0(10.7-25.3)$ & $20.7(13.5-28.4)$ \\
\hline Walk-in & $16.6(11.4-24.5)$ & $18.4(12.0-26.9)$ \\
\hline \multicolumn{3}{|l|}{ Trauma injury } \\
\hline Yes & $12.5(8.7-21.1)^{\star}$ & $15.7(8.2-27.6)$ \\
\hline No & $17.0(11.4-24.8)$ & $19.4(12.6-27.6)$ \\
\hline \multicolumn{3}{|l|}{ Abdominal pain } \\
\hline Yes & $16.0(10.9-23.3)^{\star}$ & $19.4(12.9-26.7)$ \\
\hline No & $18.0(11.5-27.6)$ & $19.3(11.6-28.2)$ \\
\hline \multicolumn{3}{|l|}{ Blood test } \\
\hline Yes & $19.8(11.8-28.5)$ & $27.9(16.4-35.8)^{\star \star}$ \\
\hline No & $16.4(10.9-24.5)$ & $18.8(11.6-26.8)$ \\
\hline \multicolumn{3}{|l|}{ Heart-rate monitoring } \\
\hline Yes & $23.1(16.2-38.6)^{\star \star}$ & $30.0(25.3-45.2)^{\star *}$ \\
\hline No & $15.6(10.7-23.1)$ & $17.8(11.3-25.7)$ \\
\hline \multicolumn{3}{|l|}{ Oxygen support } \\
\hline Yes & $20.9(12.3-34.4)^{\star \star}$ & $26.8(15.1-45.0)^{\star \star}$ \\
\hline No & $15.9(10.8-24.1)$ & $18.7(11.7-26.7)$ \\
\hline \multicolumn{3}{|l|}{ Isolation } \\
\hline Yes & $30.1(21.8-54.3)^{\star \star}$ & $35.5(22.6-57.8)^{\star \star}$ \\
\hline No & $15.9(10.8-23.8)$ & $18.5(11.6-26.7)$ \\
\hline \multicolumn{3}{|l|}{ Time of day of arrival with } \\
\hline Low LOS & $15.7(9.7-29.1)$ & $16.2(10.6-24.2)$ \\
\hline High LOS & $17.0(11.4-24.5)$ & $19.8(12.7-27.8)$ \\
\hline Continuous confounders & Spearman rank-order correlation & Spearman rank-order correlation \\
\hline Age & $0.15^{\star \star}$ & $0.22^{\star \star}$ \\
\hline Crowding & 0.03 & $0.17^{\star *}$ \\
\hline Time to patient care by physician & $0.16^{\star \star}$ & 0.06 \\
\hline Number of examinations (range $0-15$ ) & $0.34^{\star \star}$ & $0.36^{\star *}$ \\
\hline Number of specialist consultations (range $0-8$ ) & $0.31^{\star \star}$ & $0.37^{\star \star}$ \\
\hline Number of doses (range 1-7) & -0.03 & $-0.15^{\star \star}$ \\
\hline Baseline pain intensity score & 0.003 & $-0.12^{*}$ \\
\hline
\end{tabular}

IV, intravenous route of analgesia administration; LOS, length of stay. ${ }^{*} \mathrm{p}<0.05 ;{ }^{* *} \mathrm{p}<0.01$.

\section{Author affiliations}

${ }^{1}$ Department of Emergency Medicine, Research Centre, Hôpital du Sacré-Cœur de Montréal, Montréal, Québec, Canada

${ }^{2}$ Faculty of Medicine, Université de Montréal, Montréal, Québec, Canada ${ }^{3}$ Department of Surgery, Centre for Advanced Research in Sleep Medicine, Hôpital du Sacré-Cœur de Montréal, Montreal, Quebec, Canada

Contributors CS, RD and J-MC conceived the study and obtained the research funding. JP mined and analysed the data. CS drafted the manuscript, and all authors contributed substantially to its revision. CS is the guarantor. All coauthors have had the opportunity to review the final manuscript and have provided their permission to publish the manuscript.

Funding This study was supported by the Emergency Department Research Fund of Hôpital du Sacré-Cœur de Montréal.

Competing interests None.

Ethics approval The study was approved by the institutional review board and Scientific and Ethic committee of Sacré-Cœur Hospital.
Provenance and peer review Not commissioned; externally peer reviewed.

Data sharing statement No additional data are available.

Open Access This is an Open Access article distributed in accordance with the Creative Commons Attribution Non Commercial (CC BY-NC 3.0) license, which permits others to distribute, remix, adapt, build upon this work noncommercially, and license their derivative works on different terms, provided the original work is properly cited and the use is non-commercial. See: http:// creativecommons.org/licenses/by-nc/3.0/

\section{REFERENCES}

1. Bond K, Ospina MB, Blitz S, et al. Frequency, determinants and impact of overcrowding in emergency departments in Canada: a national survey. Healthc Q 2007:10:32-40.

2. Asplin BR, Magid DJ, Rhodes KV, et al. A conceptual model of emergency department crowding. Ann Emerg Med 2003;42:173-80. 
3. Health Technology Assessment. Strategies to reduce emergency department overcrowding. Alberta: Heritage Foundation for Medical Research, 2006.

4. Henneman $\mathrm{PL}$, Nathanson $\mathrm{BH}$, $\mathrm{Li} \mathrm{H}$, et al. Emergency department patients who stay more than 6 hours contribute to crowding. J Emerg Med 2010;39:105-12.

5. Taylor C. Patient satisfaction in emergency medicine. Emerg Med J 2004;21:528-32.

6. Bernstein SL, Aronsky D, Duseja R, et al. The effect of emergency department crowding on clinically oriented outcomes. Acad Emerg Med 2009;16:1-10

7. Richardson DB. The access-block effect: relationship between delay to reaching an inpatient bed and inpatient length of stay. Med J Aust 2002;177:492-5.

8. Richardson DB. Increase in patient mortality at 10 days associated with emergency department overcrowding. Med J Aust 2006;184:213-16.

9. Sprivulis PC, Da Silva JA, Jacobs IG, et al. The association between hospital overcrowding and mortality among patients admitted via Western Australian emergency departments. Med J Aust 2006;184:208-12.

10. Mowery NT, Dougherty SD, Hildreth AN, et al. Emergency department length of stay is an independent predictor of hospital mortality in trauma activation patients. J Trauma 2011;70:1317-25.

11. Miró O, Antonio MT, Jiménez S, et al. Decreased health care quality associated with emergency department overcrowding. Eur J Emerg Med 1999;6:105-7.

12. Trzeciak S, Rivers EP. Emergency department overcrowding in the United States: an emerging threat to patient safety and public health. Emerg Med J 2003;20:402-5.

13. Joint Commission on Accreditation Healthcare Organizations. Delays in treatment. Sentinel event alert 2002:1-3.

14. Hwang $\mathrm{U}$, Morrison R, Harris $\mathrm{B}$, et al. The association of ED crowding factors with quality of pain management. Acad Emerg Med 2007; 14:S54

15. Hwang U, Richardson LD, Sonuyi TO, et al. The effect of emergency department crowding on the management of pain in older adults with hip fracture. J Am Geriatr Soc 2006;54:270-5.

16. Pines JM, Hollander JE. Emergency department crowding is associated with poor care for patients with severe pain. Ann Emerg Med 2008:51:1-5.

17. Sinatra R. Causes and consequences of inadequate management of acute pain. Pain Med 2010;11:1859-71.

18. Selbst SM. Analgesic use in the emergency department. Ann Emerg Med 1990;19:1010-13.

19. Todd $\mathrm{KH}$, Ducharme J, Choiniere $\mathrm{M}$, et al. Pain in the emergency department: results of the pain and emergency medicine initiative (PEMI) multicenter study. J Pain 2007;8:460-6.

20. Todd $\mathrm{KH}$, Sloan $\mathrm{EP}$, Chen $\mathrm{C}$, et al. Survey of pain etiology, management practices and patient satisfaction in two urban emergency departments. CJEM 2002;4:252-6.

21. Silka PA. Pain scores improve analgesic administration patterns for trauma patients in the emergency department. Acad Emerg Med 2004;11:264-70.

22. Stalnikowicz R, Mahamid R, Kaspi S, et al. Undertreatment of acute pain in the emergency department: a challenge. Int J Qual Health Care 2005;17:173-6.

23. Chen $\mathrm{EH}$, Shofer FS, Dean AJ, et al. Gender disparity in analgesic treatment of emergency department patients with acute abdominal pain. Acad Emerg Med 2008;15:414-18.

24. Singer AJ, Garra G, Chohan JK, et al. Triage pain scores and the desire for and use of analgesics. Ann Emerg Med 2008:52:689-95.

25. Yakuna M, Soffer D, Halpern $P$, et al. An interventional study to improve the quality of analgesia in the emergency department. CJEM 2008;10:435-9.
26. Pines JM, Shofer FS, Isserman JA, et al. The effect of emergency department crowding on analgesia in patients with back pain in two hospitals. Acad Emerg Med 2010;17:276-83.

27. Grant PS. Analgesia delivery in the ED. Am J Emerg Med 2006;24:806-9.

28. Dunwoody CJ, Krenzischek DA, Pasero C, et al. Assessment, physiological monitoring, and consequences of inadequately treated acute pain. Pain Manag Nurs 2008;9:11-21.

29. Morrison RS, Magaziner J, Gilbert M, et al. Relationship between pain and opioid analgesics on the development of delirium following hip fracture. J Gerontol A Biol Sci Med Sci 2003;58:76-81.

30. Gonzalez ER, Bahal N, Hansen LA, et al. Intermittent injection vs patient-controlled analgesia for sickle cell crisis pain. Comparison in patients in the emergency department. Arch Intern Med 1991;151:1373-8.

31. Gardner RL, Sarkar U, Maselli JH, et al. Factors associated with longer ED lengths of stay. Am J Emerg Med 2007;25:643-50.

32. Aubrun F, Langeron O, Quesnel C, et al. Relationships between measurement of pain using visual analog score and morphine requirements during postoperative intravenous morphine titration. Anesthesiology 2003;98:1415-21.

33. Macintyre PE, Scott DA, Schug SA, et al. Acute pain management: scientific evidence. 3rd edn. Australian and New Zealand College of Anaesthetists, 2010:491.

34. Smith S, Radcliffe J. Guidelines for the management of pain in adults. Clinical Guidelines 2010.

35. Moore A, McQuay H, Gavaghan D, et al. Deriving dichotomous outcome measures from continuous data in randomised controlled trials of analgesics. Pain 1996;66:229-37.

36. Moore A, McQuay H, Gavaghan D, et al. Deriving dichotomous outcome measures from continuous data in randomised controlled trials of analgesics: verification from independent data. Pain 1997;69:127-30.

37. Joint Commission on Accreditation Healthcare Organizations. Pain: current understanding of assessment, management, and treatments 2001:92.

38. Carns P. Healthcare guideline: assessment and management of acute pain. 6th edn. Institute for Clinical Systems Improvement, 2008:58.

39. Boyd RJ. The efficacy of structured assessment and analgesia provision in the paediatric emergency department. Emerg Med $\mathrm{J}$ 2005;22:30-2.

40. Vazirani J, Knott JC. Mandatory pain scoring at triage reduces time to analgesia. Ann Emerg Med 2012;59:134-8.

41. Austin PC, Rothwell DM, Tu JV. A comparison of statistical modeling strategies for analyzing length of stay after CABG surgery. Health Serv Outcomes Res Methodol 2002;3:107-33.

42. National Institute of Clinical Studies. National Emergency Department Collaborative Final Report, Melbourne Australia's, April 2004.

43. Beveridge RC, Clarke B, Janes L, et al. Implementation guidelines for the Canadian Emergency Department Triage and Acuity Scale. Endorsed by the Canadian Association of Emergency Physicians (CAEP), the National Emergency Nurses Affiliation of Canada (NENA), and L'association des médecins d'urgence du Québec (AMUQ). 1998:1-32.

44. Wilson JE, Pendleton JM. Oligoanalgesia in the emergency department. Am J Emerg Med 1989;7:620-3.

45. Schull MJ, Guttmann A, Leaver CA, et al. Prioritizing performance measurement for emergency department care: consensus on evidence-based quality of care indicators. CJEM 2011;13:300-9.

46. Bendall JC, Simpson PM, Middleton PM, et al. Effectiveness of prehospital morphine, fentanyl, and methoxyflurane in pediatric patients. Prehosp Emerg Care 2011;15:158-65.

47. Krauss WC, Shah S, Shah S, et al. Fentanyl in the out-of-hospital setting: variables associated with hypotension and hypoxemia. J Emerg Med 2011;40:182-7. 